\title{
Research Competencies and Performance of Higher Education Institutions (HEI) Faculty
}

\author{
Adriel G. Roman \\ adriel.roman@1spu.edu.ph \\ College of Teacher Education \\ Laguna State Polytechnic University, Laguna, 4019, Philippines
}

\begin{abstract}
This study examined the research competencies and research performance higher education institutions (HEIs) faculty as to the number of researches completed, presentations, publications, and citations. The sample included 135 faculty of 8 public and private HEIs in the Philippines. Statistical treatments such as frequencies, percentages, and weighted means were used to present descriptive data while logistic regression was used to determine a suitable independent variable that fits to the model for predicting the research performance. The results revealed that the frequency of faculty in the HEIs decreases as the analysis moves from one research performance parameter to another higher parameter. The findings also indicated that research competency of the higher education institutions' faculty members is a predictor of research productivity particularly on the number of researches completed by the faculty. Several recommendations were given to increase research performance of the HEI faculty on research such as providing research trainings and mentoring programs.
\end{abstract}

Keywords: Research Competencies, Research Performance, Logistic Regression

\section{Introduction}

Research is a process of inquiry that helps human being in improving the quality of life by serving as a tool that promotes assistance in reducing burden of works. Following a cyclical process, research as explained by Plomp (2013), has no end. It is a dynamic process that starts with a problem and continues with another problem. In the present world scenario, the contribution of research in man's daily living is innumerable. In a specific instance, the vast changing world is brought about by technology which is one of the products of research. As man continues supplying his needs and satisfying his wants, the presence of research will always be realized. Hence, there is no doubt that research is a part of everyday activities of man. With these, research has been one of the priorities of the government in the national level for meeting the unlimited needs of citizens. One of the proofs is its appearance to the constitution more than five times (Article III sec 7, Art XIII sec.5,7,12,18(5), Art XIV sec. 9,10,11,18(2)). Research has been reported to have large influence in education as explained by Ary et al. (2018). The current pedagogies that teachers use nowadays are the results of previous conducted researches in addition to assessment strategies, and evaluation process.

Across the globe, research is reported as one of the parameters of success in higher education institutions (Marin, et al., 2017). This is because research involves transfer of competencies in teaching and the outputs of researches are useful in instruction and community outreach involvement. When a certain HEI has evident research outcomes, the quality of instruction is justified and the potential for sustainability of community services (extensions) gets high. In the Philippines, the idea of research is supported by various educational agencies such as the Commission on Higher Education (CHED), the Technical Education and Skills Development Authority (TESDA), and Department of Education (DepEd) as reflected on various research 
fora conducted local and international every year. The CHEd formulated policies and guidelines to promote research among teachers. These policies are supported by the availability of funds to encourage teachers to propose and make researches. In fact, research in higher education is included in the four-fold functions of faculty especially in State Universities and Colleges (SUCs) in addition to instruction, extension and production. Through this, it is imperative for every faculty in the Higher Education Institutions to conduct research and other scholarly investigations in the various academic discipline to develop and nurture a research culture among the people (CMO 32, s. 2008). The presented scenario of research in the Philippine educational system calls for a comprehensive research that looks at the culture of research in Higher Educational Institutions.

The Higher Education Institutions in the Philippines is consisted of 111 State Universities and Colleges (SUC)(excluding satellite campuses while 558 in the inclusion of satellites), 108 Local Universities and Colleges (LUCs), 14 Other Governmental Schools (OGS, CSI, Special HEIs), and 1,673 Private Higher Education Institutions (PHEIs) with a total of 1,906 Higher Education Institutions (2,353 if satellites are included) (CHEd Knowledge Management Division, 2018).

Research is given high regards in the evaluation of programs and institutions of higher learning in the Philippines. In the Joint Circular No. 1 s. 2016 of the Department of Budget and Management (DBM) and Commission on Higher Education about the SUC Levelling Instrument, research capability output is given 14 points out of 51. Same scenario is given to research when focusing on institutional accreditation. Despite of being voluntary method of quality assurance, many higher education institutions were subjected to accreditation. Accreditation has been one of the indicators of the performance of higher education institutions in the Philippines after the issuance of the revised policies and guidelines on voluntary accreditation in support to quality and excellence in higher education (Ching, 2003). In the accreditation process, research is seen as one of the salient parameters measured by several accrediting bodies.

The Association of Accredited Chartered Colleges and Universities in the Philippines (AACCUP) highlighted the significance of research in their instrument for accreditation similar to program accreditation of the AACCUP. For private colleges and universities, research is one among the 10 areas for program accreditation as defined by the Accreditation Instrument of the Philippine Association of Colleges and Universities Commission on Accreditation (PACUCOA) and Philippine Accrediting Association of Schools, Colleges and Universities (PAASCU). When it comes to local universities and colleges, research is one among the 9 parameters for accreditation of Association of Local Colleges and Universities Commission on Accreditation (ALCUCOA) in addition to employability and entrepreneurship, governance and administration, curriculum and instruction, faculty, student development services, extension services/community involvement, laboratories, and physical plant. In addition, as key leader of Higher Education, CHEd has made necessary steps in encouraging professors and instructors to make researches that meet the problem faced by education in the country. Hence, with the aforementioned parameters of different higher educational institution accrediting agencies and the steps made by the CHEd, it is expected that each institution performs well in research.

On the contrary, despite these initiatives and parameters, reports and results of studies confirmed that there is a weak research culture in education (Salazar-Clemeña and Acosta (2007)) due to insufficiency of research skills and knowledge training of teachers in doing research (Ellis \& Loughland, 2016; Vásquez, 2017) and poor and inadequate research in the higher education (CHED Accomplishment 2010-2016). Ayala and Garcia (2013) concluded that in CALABARZON, there are research outputs presented in scientific conferences but lacking of publications to refereed journals, utilization for development and institutional changes or innovation, and commercialization in which found lesser than $25 \%$ of the research outputs. 


\section{Objectives}

The primary focus of the study is to determine the research competencies and research performance of faculty in the higher education institutions in the Philippines. It also tries to use logistic regression in creating a model on predicting the research performance of the faculty using their research competencies. Finally, a research mentoring program is developed.

\section{Methodology}

The study utilized the descriptive design of research that focuses on describing the characteristics of the population and phenomenon being studied (Ethridge, 2004). This study was conducted in eight public and private higher educational institutions in one province in the Philippines. A total of 135 HEIs faculty participated in the study. The researcher prepared research instrument which was content validated by the panel of evaluators together with external experts in the field of research. The instrument was also validated by 30 doctorate students in one state university and likewise undergone pilot testing to 30 faculty members of one state university in the Philippines. The Cronbach's alpha of measuring the reliability was 0.946 insinuating high reliability. The validated instrument was distributed to 135 faculty of eight selected public and private HEIs. The same research instrument floated to the respondents were collected on the specific date the researcher and the respondents agreed upon. The data gathered were encoded and classified according to the parameters of interest and were tabulated, analyzed and interpreted using frequencies, percentages, weighted mean and logistic regression. To measure the research competency of HEI faculty, a 75-item validated test was used. Competencies in problems and backgrounds, literatures, sources and citations, theories and frameworks, research types, methods, instrumentations, sampling techniques, research ethics, data analysis procedures, and giving interpretations, conclusions, recommendations, and implications were utilized as parameters. To determine the research performance of the faculty, the researcher asked also the number of researches completed, presented, published, and cited for the past 3 years. Finally, the logistic regression analysis following the procedures given by Peng, Lee and Ingersoll (2002) was used.

\section{Results and Discussions}

The research competencies of the HEI faculty based on the research competency test reveals generally a low extent $(32.56 \%)$. In particular, competencies about problems and backgrounds, literatures, sources and citations, theories and frameworks, research methods, research instrumentations, sampling techniques, research ethics, data analysis procedures, and making interpretation, conclusion, recommendation and implication are all in the low extent category while the competency of the HEI faculty in research types is on the average level. The result also reflects that among the 10 parameters, competency about research ethics is at the bottom. This result about research competencies of the respondents as reflected on the research competency test shows that there is a need to upgrade the competency level in research in all aspects. Knowledge on research ethics is a major result that found low extent in the study. The importance of research ethics has been neglected by some of the researches for a long period of time. Ethical consideration should always be given to the participants/respondents, setting, among others. If neglected, there research findings and outputs specifically published outputs would be leading to a malpractice particularly in research methodology or procedure. Similar to what Resnik (2015) mentioned that research ethical lapses can cause harm to subjects, students, and the general public. The findings presented are conformant to the result of the study conducted by Bueno (2017) in one university in the Philippines that faculty still need to improve mastery of research skills as shown by their own outputs, provision of assistance to graduate students in developing competencies in research, and professional growth through further research endeavors. 
Table 1. Research Competencies of HEI Faculty as Reflected on the Research Competency Test

\begin{tabular}{lccc}
\hline Parameter & $\begin{array}{c}\text { Number of } \\
\text { Items }\end{array}$ & $\begin{array}{c}\text { Research } \\
\text { Competencies }\end{array}$ & Percentage \\
\hline Problems and Backgrounds & 9 & 2.93 & $32.59 \%$ \\
Literatures, Sources and Citations & 7 & 2.15 & $30.69 \%$ \\
Theories and Frameworks & 6 & 2.22 & $37.04 \%$ \\
Research Types & 7 & 3.06 & $43.70 \%$ \\
Research Methods & 8 & 2.64 & $32.96 \%$ \\
Research Instrumentations & 9 & 3.13 & $34.81 \%$ \\
Sampling Techniques & 9 & 3.13 & $34.81 \%$ \\
Research Ethics & 6 & 1.26 & $20.99 \%$ \\
Data Analysis Procedures & 9 & 2.71 & $30.12 \%$ \\
Interpretation, Conclusion, Recommendation and & & & $23.70 \%$ \\
Implication & 5 & $\mathbf{2 4 . 4 2}$ & $\mathbf{3 2 . 5 6 \%}$ \\
\hline OVERALL & $\mathbf{7 5}$ & $\mathbf{2 4 . 4 2}$ & \\
\hline
\end{tabular}

Data presented in table 2 shows that out of 135 HEI faculty-respondents, $51.11 \%$ has completed research paper against $48.89 \%$ respondents with no completed research papers. In terms of research presentation to forums and conferences, $26.67 \%$ of the respondents answered that they experienced presenting research to local, regional, national or international conferences/fora. When it comes to paper publication to research journals, 15 or $11.11 \%$ of the respondents answered that they have at least one research paper publication to research journals in which 7 out of 15 respondents with publications are able to obtain research citations.

The result of the study about the research performance of HEI faculty in terms of the identified parameters revealed that only half of the respondents were able to complete research project/study. Surprisingly, the frequency decreases as the analysis moves from one parameter to another. This signifies that not all HEI faculty are presenting or publishing research papers which is considered by Mantikayan and Abdulgani (2018) as the visible proof of being an active researcher. Similarly, data about the number of completed research and number of published papers denote that after the completion of the research study/project, the research findings were not disseminated through publication. The domino effect of this minimal number of publications is the lower percentage of respondents with citations.

The findings of the study agreed to the conclusion of Cocal and Celino (2017) that research productivity of faculty is very low in which less than half of the faculty members were conducting research and only quarter of them were able to present the output of their research in local, regional, national, and international conferences while less than $10 \%$ of the faculty have published papers.

Table 2. Research Performance of HEI Faculty in Terms of the Number of Research Competed, Presented, Published, and

\begin{tabular}{ccccccc}
\multicolumn{1}{c}{ Cited } & Total & $\%$ \\
\hline Research Performance & With & $\%$ & Without & $\%$ & Tot \\
Completed & 69 & 51.11 & 66 & 48.89 & 135 & 100.00 \\
Presented & 36 & 26.67 & 99 & 73.33 & 135 & 100.00 \\
Published & 15 & 11.11 & 120 & 88.89 & 135 & 100.00 \\
Cited & 7 & 5.19 & 128 & 94.81 & 135 & 100.00 \\
\hline
\end{tabular}

The model summary for identifying research competency associated with the number of completed research of the respondents shows that the Wald Chi-square value 9.155 is statistically significant denoting that the model can validly predict the number of researches completed using the respondents research competency test results. Likewise, based on the Hosmer and Lemeshow test, the p-value of 0.073 being greater than 0.05 alpha level of significance, denote that the model fits the data well. On the other hand, the 
research competency test results do not significantly predict the number of presented researches of the respondents $\left(\chi^{2}=3.742 ; p>0.05\right)$. Same result is obtained on the number of research publication $\left(\chi^{2}=3.380 ; p>0.05\right)$, and number of citations $\left(\chi^{2}=1.483 ; p>0.05\right)$.

Table 3. Logistic Regression Model for Predicting Research Performance of HEI Faculty in Terms of the Number of Research Completed, Presented, Published, and Cited Using their Research Competency Test Result

\begin{tabular}{|c|c|c|c|c|c|c|c|}
\hline $\begin{array}{c}\text { Dependent } \\
\text { Variable }\end{array}$ & Predictor & B & S.E. & Wald $\left(\chi^{2}\right)$ & $\mathrm{df}$ & Sig. & $\operatorname{Exp}(B)$ \\
\hline \multirow{7}{*}{ Completed } & Research Competency & 0.043 & 0.014 & 9.155 & 1 & 0.002 & 1.044 \\
\hline & Constant & -1.015 & 0.395 & 6.609 & 1 & 0.010 & 0.362 \\
\hline & Model Coefficients & & & $\chi^{2}$ & df & Sig. & \\
\hline & Step & & & 10.099 & 1 & 0.001 & \\
\hline & Block & & & 10.099 & 1 & 0.001 & \\
\hline & Model & & & 10.099 & 1 & 0.001 & \\
\hline & Hosmer and Lemeshow Test & & & 12.982 & 7 & 0.073 & \\
\hline \multirow{7}{*}{ Presented } & Research Competency & 0.031 & 0.016 & 3.742 & 1 & 0.053 & 1.031 \\
\hline & Constant & -1.796 & 0.468 & 14.721 & 1 & 0.000 & 0.166 \\
\hline & Model Coefficients & & & $\chi^{2}$ & $\mathrm{df}$ & Sig. & \\
\hline & Step & & & 3.989 & 1 & 0.046 & \\
\hline & Block & & & 3.989 & 1 & 0.046 & \\
\hline & Model & & & 3.989 & 1 & 0.046 & \\
\hline & Hosmer and Lemeshow Test & & & 10.508 & 7 & 0.162 & \\
\hline \multirow{7}{*}{ Published } & Research Competency & 0.043 & 0.023 & 3.380 & 1 & 0.066 & 1.044 \\
\hline & Constant & -3.245 & 0.747 & 18.884 & 1 & 0.000 & 0.039 \\
\hline & Model Coefficients & & & $\chi^{2}$ & $\mathrm{df}$ & Sig. & \\
\hline & Step & & & 3.730 & 1 & 0.053 & \\
\hline & Block & & & 3.730 & 1 & 0.053 & \\
\hline & Model & & & 3.730 & 1 & 0.053 & \\
\hline & Hosmer and Lemeshow Test & & & 10.496 & 7 & 0.162 & \\
\hline \multirow{7}{*}{ Cited } & Research Competency & 0.04 & 0.032 & 1.483 & 1 & 0.223 & 1.040 \\
\hline & Constant & -3.989 & 1.053 & 14.346 & 1 & 0.000 & 0.019 \\
\hline & Model Coefficients & & & $\chi^{2}$ & $\mathrm{df}$ & Sig. & \\
\hline & Step & & & 1.606 & 1 & 0.205 & \\
\hline & Block & & & 1.606 & 1 & 0.205 & \\
\hline & Model & & & 1.606 & 1 & 0.205 & \\
\hline & Hosmer and Lemeshow Test & & & 5.253 & 7 & 0.629 & \\
\hline
\end{tabular}

The result of the logistic regression analysis denotes that research productivity of the teacher is directly affected by his or her research knowledge and skills. When the teacher has enough competency in doing research, there is a bigger chance that he or she can accomplish or produce a research study/project. On the other hand, when there is insufficiency on the basic competencies in research, chances are minimal that the teacher can accomplish a certain research study/project. Although research findings show no significant implication about predicting number of researches presented, published, and cited using the research competencies of the teachers, it is worthy to note that completed research is a pre-requisite before one can present (a completed paper), publish, and has citations. For this reason, to increase the number of researches produced by the faculty, the research competency should be levelled up. As what Ramos (2017) found out in 
his study that in terms of quality of action research proposals of the teacher participants, needs improvement level were found on making: review of related literature; formulating research questions; choosing research design; ethical issues; clarity of expression; and format and style. Hence the result conforms to what Ulla et al. (2017) concluded that despite being one of the functions in higher education, teachers opted not to undertake research due to the identified determinants such as personal behavior, experiences, research needs, lack of research knowledge and skills, ancillaries, and lack of school's financial support.

Table 4 shows that among the 10 parameters of research competency test, data analysis procedures and giving interpretation are the most significant predictors of research performance of the respondents in terms of number of researches completed. This result denotes that a faculty can accomplish more research study/projects if he/she has enough competencies in terms of data processing and procedures. Surprisingly, faculty who has enough competencies in interpreting results, providing conclusions, recommendations, and implications has lesser number of researches completed. This result implied that when one needs to produce research, consultation may be done with the faculty who can analyze the data provide data analysis procedures whether what type of data would be analyzed. In addition, findings confirm that it is not enough that faculty know the different parts of research but also how to perform data analysis procedures. Knowledge on data analysis procedure is needed prior to the interpretation of research results. In this process, the data output (calculated) needs to be keenly and carefully analyzed or treated. When incorrect treatment is applied to the data an incorrect result will be generated which leads to wrong interpretation and misleading conclusions. Having knowledgeable in this part of research is important in determining applicable analysis treatment whether quantitative or qualitative. Without knowledge on proper data analysis procedure, it is impossible for a researcher to provide proper interpretation of the result. In particular instance, treatments on determining significant relationship (Pearson's $\mathrm{r}$ : parametric data) is quite different from determining or establishing significant difference (t-test: parametric data). According to Etcuban et al. (2016) most of the teachers have low research outputs and likewise needing research trainings specifically in methodologies (methods) and data analysis procedures (statistics).

Table 4. Logistic Regression Model for Predicting Research Performance of HEI Faculty in Terms of the Number of Research Completed Using their Research Competency Test Result

\begin{tabular}{lcccccc}
\hline Predictor & B & S.E. & Wald $\left(\chi^{\mathbf{2}}\right)$ & df & Sig. & Exp(B) \\
\hline Problems and Backgrounds & .098 & .166 & .348 & 1 & .555 & 1.103 \\
Literatures, Sources... & .231 & .183 & 1.595 & 1 & .207 & 1.259 \\
Theories and Frameworks & -.027 & .199 & .018 & 1 & .893 & .974 \\
Research Types & .140 & .106 & 1.753 & 1 & .185 & 1.150 \\
Research Methods & .166 & .220 & .570 & 1 & .450 & 1.181 \\
Research Instrumentations & .015 & .150 & .009 & 1 & .923 & 1.015 \\
Sampling Techniques & -.239 & .153 & 2.442 & 1 & .118 & .787 \\
Research Ethics & -.059 & .202 & .085 & 1 & .771 & .943 \\
Data Analysis Procedures & .459 & .181 & 6.461 & 1 & .011 & 1.583 \\
Interpretation, Conclusion... & -.813 & .256 & 10.069 & 1 & .002 & .444 \\
Constant & -1.030 & .417 & 6.094 & 1 & .014 & .357 \\
\hline
\end{tabular}

\section{Conclusion, Recommendation and Limitations}

This study tried to determine the research competencies and research performance of faculty in the higher education institutions in the Philippines. It also tried to determine a predicting model for measuring the research performance of the faculty using their research competencies. Generally, the respondents of the study have low research competencies in nine out of the 10 parameters except for knowledge on research types. Also, there is a decrease in numbers for every increase in the hierarchy of research productivity from completed to cited research. For this reason, it is reasonable to conclude that faculty in the HEIs are 
completing research studies/projects but fall short on presentation and publication. Likewise, the study is able to determine that research competency of the higher education institutions' faculty members is a predictor of research productivity particularly on the number of researches completed by the faculty. Knowledge on data analysis is a positive determinant of having higher number of researches completed by the HEI faculty.

\section{Recommendations and Limitations}

With this, it is recommended to provide necessary steps in order to increase research competencies of the HEI faculty on research. This can be done through providing research trainings and mentoring programs since it was found that there are about $10 \%$ of the faculty with published papers. Though this study successfully generated conclusion that can be added to the body of knowledge, it has several limitations. The researcher tried to include a larger number of respondents. However, not all respondents identified were able to finish the research competency test. Also, the research competency test was a multiple-choice type of test given to the respondents and no subjective type of survey was given to them to measure the same variable. Thus, research competency discussed in the paper pertains solely to the result of the multiple-choice test.

\section{Acknowledgements}

The author wishes to thank the Laguna State Polytechnic University for supporting this study.

\section{References}

Ary, D., Jacobs, L. C., Irvine, C. K. S., \& Walker, D. (2018). Introduction to research in education. Cengage Learning.

Ayala, C. J. \& Garcia, B. H.. (2013). Research Productivity and Utilization in Higher Education Institutions in the CALABARZON Region. MSEUF Research Studies, 15(1). Retrieved from http://ejournals.ph/form/cite.php?id =6751

Bueno, D. C.. (2017). Research Skills of the Professorial Lecturers: Input to Capability Building. JPAIR Institutional Research Journal, 9(1). Retrieved from http://ejournals.ph/form/cite.php?id=12147

CHED Accomplishment 2010-2016

Ching, G. S. (2013). Higher education accreditation in the Philippines: A. International Journal, 2(1), 63-74.

CMO 46, s. 2012. Policy-Standard to Enhance Quality Assurance (QA) in Philippine Higher Education Through An Outcomes-Based and Typology-Based QA

CMO 32, s. 2008. Revised Guidelines for the CHED Best Higher Education Institution (HEI) Research Program Award

Cocal, C., Cocal E.,\& Celino, B. (2017). Factors Limiting Research Productivity of Faculty Members of a State University: The Pangasinan State University Alaminos City Campus Case. Asia Pacific Journal of Academic Research in Social Sciences, 2 (43-48).

DBM-CHEd Circular No. 1 series 2016. SUC Levelling Instrument and Guidelines for the Implementation Thereof.

Ellis, N. \& Loughland, T. (2016). The challenges of practitioner research: A comparative study of Singapore and NSW. Australian Journal of Teacher Education, 41(2) http://dx.doi.org/10.14221/ajte.2016v41n28

Etcuban, J. O., Andrin, G. R., Niñal, M. M., Campanilla, B. S., Dinauanao, A. M., Macugay, P. J. D., \& Belarmino, G. A. (2016). Research Productivity among Faculty Members of the University of Cebu, Philippines. JPAIR Institutional Research, 8(1), 20-40. 
Ethridge, D.E. (2004) "Research Methodology in Applied Economics" John Wiley \& Sons, p.24. Retrieved from: https://researchmethodology. net/descriptive-research/

Mantikayan, J. M., \& Abdulgani, M. A. (2018). Factors Affecting Faculty Research Productivity: Conclusions from a Critical Review of the Literature. JPAIR Multidisciplinary Research, 31(1).

Marin, E.; Iftimescu, S.; Ion, G.; Stingu, M.; Proteasa, C. (2017). Academic Managers` Perspective on Research Management in Higher Education Institutions across Romania. En Proceedings of the 3rd International Conference on Higher Education Advances.

Peng, C. Y. J., Lee, K. L., \& Ingersoll, G. M. (2002). An introduction to logistic regression analysis and reporting. The journal of educational research, 96(1), 3-14.

Plomp, T. (2013). Educational design research: An introduction. Educational design research, 11-50.

Ramos, W. A. (2017). EFFECTS OF RESULT-BASED CAPABILITY BUILDING PROGRAM ON THE RESEARCH COMPETENCY, QUALITY AND PRODUCTIVITY OF PUBLIC HIGH SCHOOL TEACHERS. PEOPLE: International Journal of Social Sciences, $3(1)$.

Resnik, J. P. (2015, December 1). What is Ethics in Research \& Why is it Important? Retrieved from National Institute of Environmental Health Sciences: https://www.niehs.nih.gov/research/resources/bioethics/whatis/index.cfm

Salazar-Clemeña, R. M., \& Almonte-Acosta, S. A. (2007, September). Developing research culture in Philippine higher education institutions: Perspectives of university faculty. In regional seminar "Competition, cooperation and change in the academic profession: Shaping higher education's contribution to knowledge and research.” Hangzhou, China (pp. 1-13).

The 1987 Constitution of the Republic of the Philippines

Ulla, M. B., Barrera, K. I. B., \& Acompanado, M. M. (2017). Philippine classroom teachers as researchers: Teachers' perceptions, motivations, and challenges. Australian Journal of Teacher Education (Online), 42(11), 52. 